\title{
Bacterial immunostimulants in recurrent paediatric respiratory infections
}

Sri Lanka Journal of Child Health, 2011; 40: 43-44

(Key words: Bacterial immunostimulants; paediatric; recurrent respiratory infections)

The defence mechanisms of the human body can be induced to provide immunity against bacteria by natural processes following infection or as a consequence of therapeutic and preventive medical intervention including vaccination, administration of immunoglobulins and therapy with immunostimulants derived from bacteria ${ }^{1}$.

From the time of the $18^{\text {th }}$ century when Edward Jenner first postulated the notion of prevention of disease by immunisation, many scientists have been striving tirelessly to produce vaccines against infective diseases that were known to cause considerable morbidity, mortality and in some cases, permanent disability. There are currently such vaccines against several bacterial and viral diseases. The fundamental principle is to induce the human immune system to produce special and specific immunity against a given infective agent. In that sense, each disease requires a specific vaccine.

Immunity is a multifaceted phenomenon and immunostimulation has been defined by various means but the exact meaning of the event defies accurate and specific delineation. It is perhaps better understood as the process of maintaining the immune system in a "state of alert" that is capable of efficiently handling microbial infections ${ }^{2}$.

In recent years, the use of refined bacterial products to produce non-specific enhanced immunity has come to the fore. Two types of compounds that have been mostly studied are microbial ribosomal vaccines and bacterial lysates. Ribosomes are cell components that create proteins from amino acids. The DNA sequence in genes is copied into a messenger RNA and the ribosomes then read the information in this RNA and use it to create proteins $^{3}$. Ribosomal vaccines have been assimilated from several different types of organisms and many of these preparations offer a higher degree of protection than do vaccines made from the homologous whole cells ${ }^{4}$. Bacterial lysates are mixtures of bacterial antigens derived from different inactivated pathogenic bacteria. They are of two types. One is polyvalent chemical bacterial lysates (PCBL) obtained by chemical lysis of the organisms and the other is polyvalent mechanical bacterial lysates (PMBL) created by mechanical lysis of the microbes. PMBL are thought to be superior to PCBL as the use of chemicals in the latter tends to induce changes in the structure of proteins and hence alter their antigenicity.

Bacterial immunostimulants that contain either ribosomal extracts or bacterial lysates have been shown to induce a non-specific intensification of phagocytosis as well as orchestration of both cellular and humoral responses. The duality of their immunomodulatory activity mimics or attempts to repeat the immune response evoked by the intrusion of a pathogen into the human body, which is initially non-specific, but subsequently becomes specific $^{1}$.

Ribosomal vaccines have been shown to be effective in the prevention of recurrent ear, nose and throat infections in young children, ${ }^{5,6}$ and paediatric recurrent lower respiratory tract infections ${ }^{7,8}$. The preparation in use most commonly has the advantage that it is administered orally.

A considerable amount of work has also been done on PMBL. The earliest study was on its effectiveness in periodontitis ${ }^{9}$. Subsequently the efficacy has been demonstrated in respiratory infections ${ }^{10-14}$. PMBL too has the advantage that it is administered sublingually. More recently, encouraging animal experiments have suggested that PMBL may have a role to play in asthma too ${ }^{15}$. However, this needs to be confirmed in human studies.

It is an established fact that recurrent respiratory infections cause significant morbidity and disturbances to the quality of life in children. The bacterial immunostimulants are yet another modality of management that would help in alleviating the problems caused by these infections. Yet for all that, these should not be considered to be a "panacea for all ills" in recurrent paediatric respiratory diseases. Unfortunately, these immunostimulants are not available in the government hospitals in our country but some of them are available in the private sector. 


\section{References}

1. Roży A, Chorostowska-Wynimko J. Bacterial immunostimulants - mechanism of action and clinical application in respiratory diseases. Pneumonologia i Alergologia Polska 2008; 76: 353-9.

2. Jindal SK. Immunostimulation - Does it work in COPD. Chest 2004; 126 (5):1406-8.

3. Ribosome. Available from: http://en.wikipedia.org/wiki/Ribosome. Accessed 3rd May 2011.

4. Gregory RL. Microbial ribosomal vaccines. Reviews of Infectious Diseases 1986; 8(2):20817.

5. Vautel JM, Cauquil J, Perruchet AM, Thomas AM. Prevention of recurrent ear, nose, and throat infections in young children with ribomunyl $\AA$ : Double-blind, placebo-controlled study. Current Therapeutic Research 1993; 53:722-9.

6. Slapak I, Cervenka J, Kosar K. Effectivity and safety of ribomunyl in children. Pediatric Research 1999; 45(5):757.

7. Bousquet J, Fiocchi A. Prevention of recurrent respiratory tract infections in children using a ribosomal immunotherapeutic agent: a clinical review. Paediatric Drugs 2006; 8(4):235-43.

8. Boyle P, Bellanti JA, Robertson C. MetaAnalysis of published clinical trials of a ribosomal vaccine (Ribomunyl) in prevention of respiratory infections. Bio Drugs 2000; 14(6):389-408.

9. Oehling A, Baena-Cagnani CE, Neffen $\mathrm{H}$. Bacterial immunotherapy of childhood bronchial asthma. Allergol Immunopathol (Madr) 1980; 8:177-84.
10. Zagar S, Lofler-Badzek D. Broncho-Vaxom in children with rhinosinusitis: a double-blind clinical trial. ORL J Otorhinolaryngol Relat Spec 1989; 50:397-404.

11. Collet JP, Ducruet T, Kramer MS, Haggerty J, Floret D, Chomel JJ, Durr F. Stimulation of nonspecific immunity to reduce the risk of recurrent infections in children attending daycare centres. The Epicreche Research Group. Pediatr Infect Dis J 1993; 12:648-52.

12. Gutiérrez-Tarango MD, Berber A. Safety and efficacy of two courses of OM-85 BV in the prevention of respiratory tract infections in children during 12 months. Chest 2001; 119:1742-8.

13. Schaad UB, Mütterlein R, Goffin H, and on behalf of the BV-Child Study Group Immunostimulation with OM-85 in children with recurrent infections of the upper respiratory tract: A double-blind, placebocontrolled multicenter study. Chest 2002; 122:2042-9.

14. Schaad UB. OM-85 BV, an immunostimulant in paediatric recurrent respiratory tract infections: a systematic review. World Journal of Pediatrics 2010; 6(1):5-12.

15. Navarro S, Cossalter G, Chiavaroli C, Kanda A, Fleury S, Lazzari A, et al.. The oral administration of bacterial extracts prevents asthma via the recruitment of regulatory $\mathrm{T}$ cells to the airways. Mucosal Immunology 2011; 4:53-65.

\section{B J C Perera}

Joint Editor 